\title{
The performance of Beck's life style multi-component model on modifying eating behavior of overweight women
}

\author{
Fariba Parsamanesh ${ }^{1}$, Adis Kraskian ${ }^{2}$, Hasan Ahadi $^{3}$, Mohammad Hakami $^{2}$ \\ ${ }^{1} \mathrm{PhD}$ in Health Psychology, Psychology Department, Psychology Faculty, Karaj Branch, Islamic Azad University, \\ Karaj, Iran \\ ${ }^{2}$ Assistant Professor of Psychology, Psychology Department, Psychology Faculty, Karaj Branch, Islamic Azad \\ University, Karaj, Iran \\ ${ }^{3}$ Professor of Psychology, Psychology Department, Psychology Faculty, Karaj Branch, Islamic Azad University, Karaj, \\ Iran
}

\begin{abstract}
Background: The role psychological models is important in creating and modifying behaviors such as weight-related behaviors. The present study was conducted to investigate the effectiveness of the Beck's multi-component model of weight-related lifestyle (2009) on eating behaviors of overweight female in Karaj city.

Materials and methods: This quasi-experimental study, using a pre-test post-test with expanded control group, was conducted on 40 female overweight students of Azad University of Karaj, Iran in 2016. The study population $(\mathrm{n}=40)$ was selected by through available sampling method and randomly divided into experimental $(m=20)$ and control $(n=20)$ groups. The experimental group subjected to eight 90 -minute sessions of the Beck's multi-component model of weight-related lifestyle (2009). The two study groups filled out the Doch Eating Behavior Questionnaire. The data were analyzed by mixed ANOVA.

Results: The results showed a significant difference between control and experimental group (betweensubjects effects) in the overall, external, and restrained eating behavior. A significant difference in the measurement period (within-subjects effects) in the overall, emotional, and external eating behavior, and a significant difference between control and experimental group and in the measurement period (Interaction effect) in eating behavior and its components (emotional, external, restrained) was observed $(\mathrm{p}<0.05)$.

Conclusion: Findings of the present study indicated the Beck's multi-component model of weight-related lifestyle (2009) can be used as an effective way to moderate eating behavior and its components (emotional, external, and restrained) in overweight women.
\end{abstract}

Keywords: Beck's model, Lifestyle, Eating behavior.

Cited as: Parsamanesh F, Kraskian A, Ahadi H, Hakami M. The performance of Beck's Life Style Multi-component Model,on modifying eating behavior of overweight women. Medical Science Journal of Islamic Azad University, Tehran Medical Branch 2019; 29(1):71-82.

Correspondence to: Adis Kraskian

Tel: +989126087538

E-mail: adis.kraskian@kiau.ac.ir

ORCID ID: 0000-0001-5026-3683

Received: 11 Mar 2018; Accepted: 3 Sep 2018 
مجله علوم يزشكى دانشعاه آزاد اسلامى

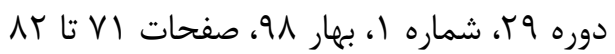

Original

Article

\section{كارايى مدل جند مولفهاى سبك زندَّى بك بر تعديل رفتار خوردن زنان بيش وزن}

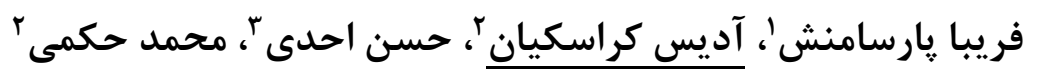

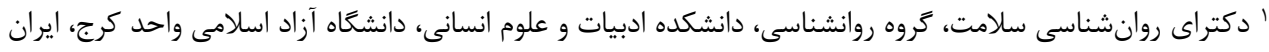

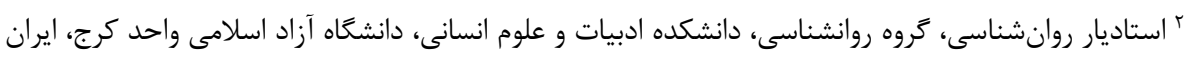

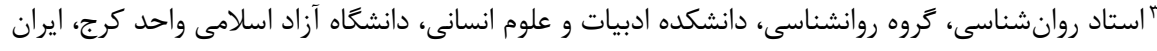

קكيده

سابقه و هدف: با توجه به اهميت مدل هاى روانشناختى بر اصلاح رفتارها از جمله رفتارهاى مرتبط با وزن، بزوهش حاضر با هاب هدف

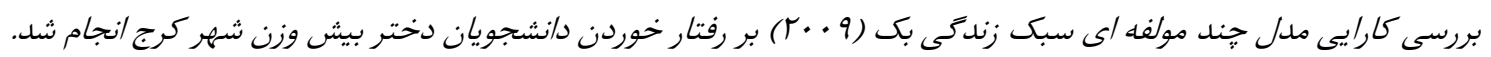

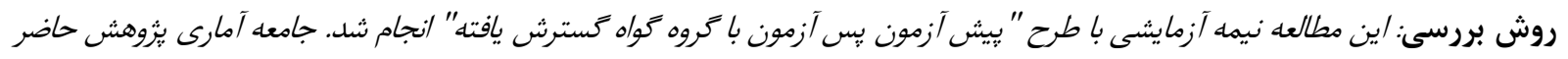

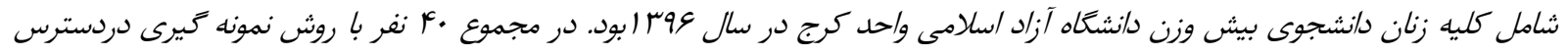

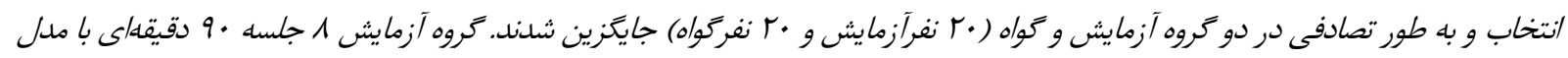

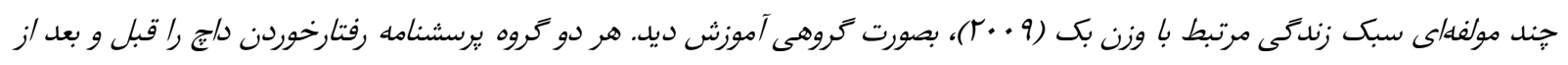

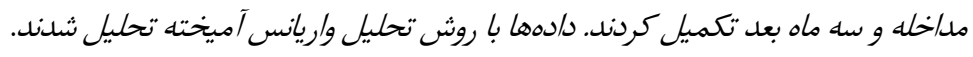

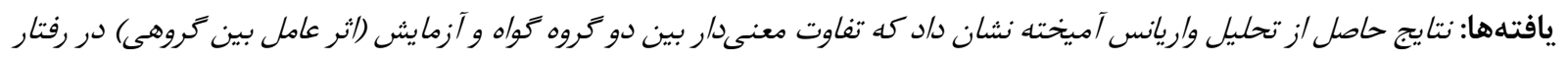

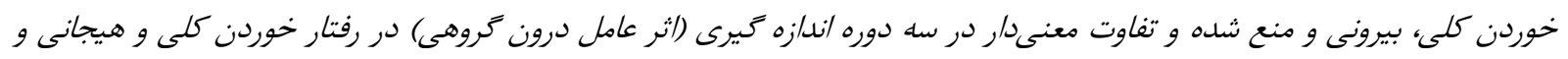

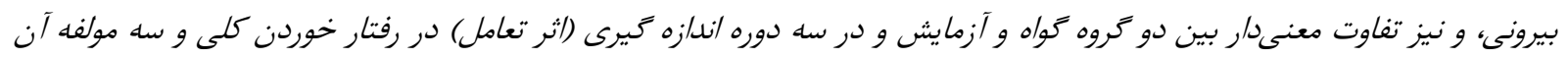

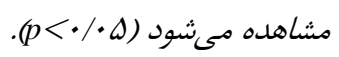

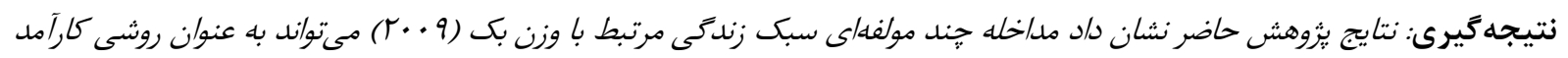

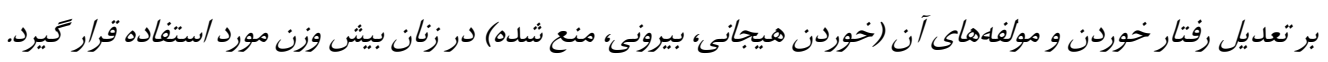
وازَّان كليدى: مدل بك، سبك زندكى، رفتارخوردن.

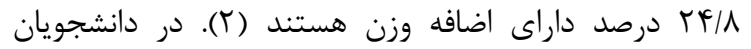
مقدمه

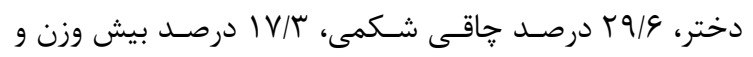

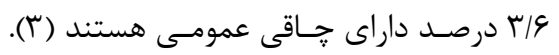

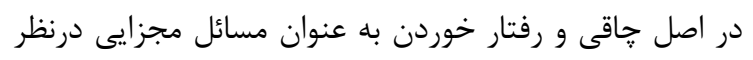

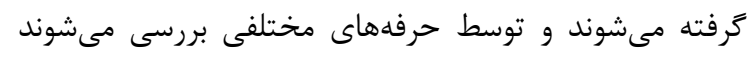

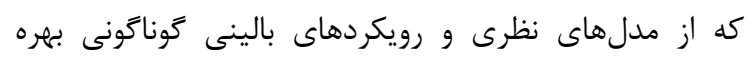
مى

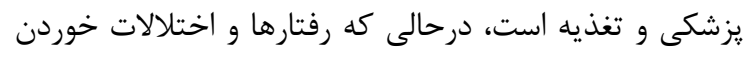

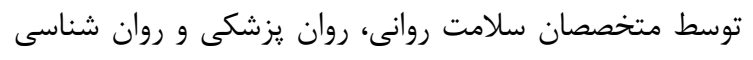

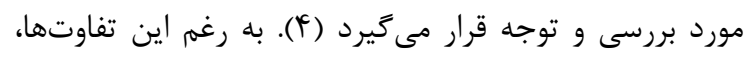

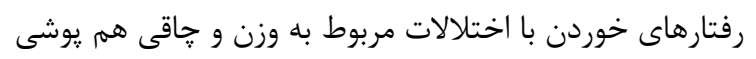

وزن ايدهال و نرمال به عنوان يكى از شاخصهاى سلامت

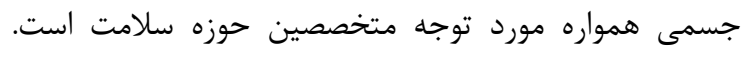

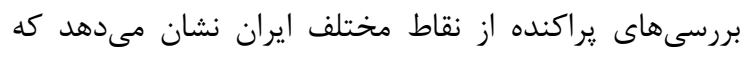

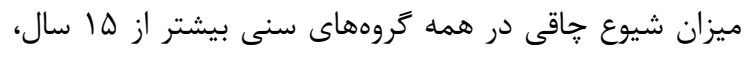

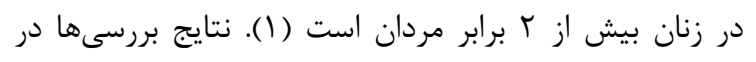

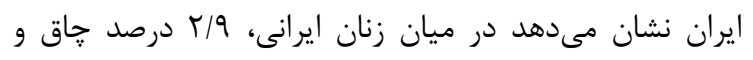

آدرس نويسنده مسئول: كرج، دانشكده ادبيـات و علـوم انسـانى، دانشـاه آزاد واحسـكرج، دكتـر آديسس (email: adis.kraskian@kiau.ac.ir) كراسكيان ORCID ID: 0000-0001-5026-3683 تاريخ دريافت مقاله: • ت •

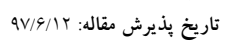


سالمترى داشتند (1)). در اين راستا سازمان بهداشت جهانى (World Health Organization(WHO))

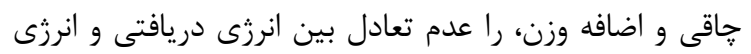
مصرفى به دليل سبك زندگى ناسالم شهرنشينى مى مداند.

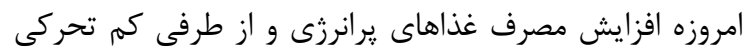

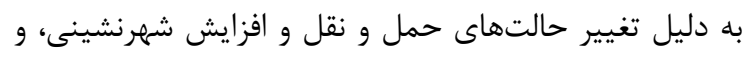

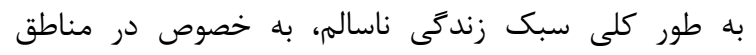

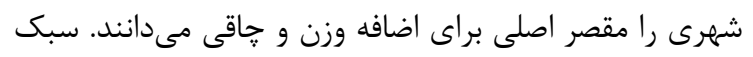

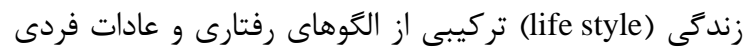

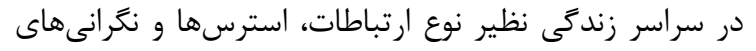

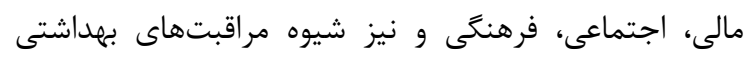

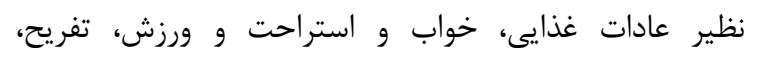

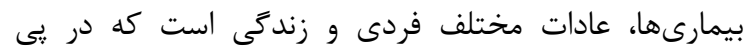

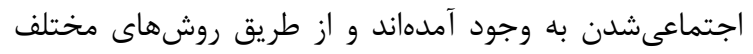
روان درمانى نظير رفتار درمانى شناخت درمانى و... قابل تغيير

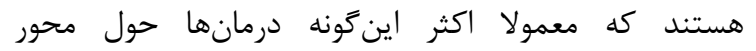

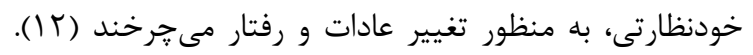

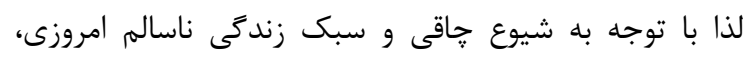

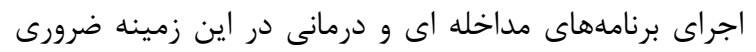

بر اساس مطالعات، مديريت طولانى مدت كاهش وزن كار كار بسيار دشوارى است كه با خطر بالاى شكست و بركشت وزيت مدرن

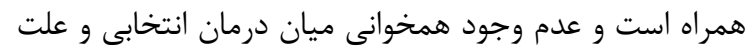

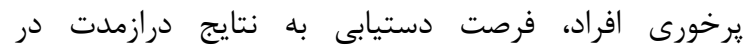

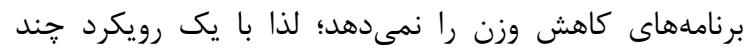

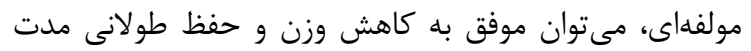

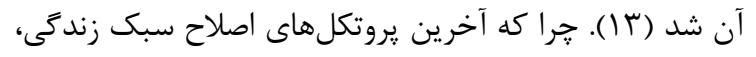

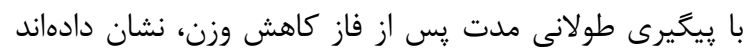

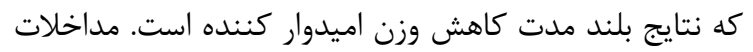

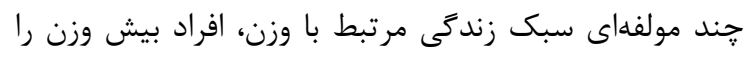

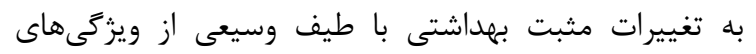

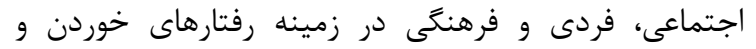

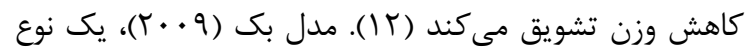

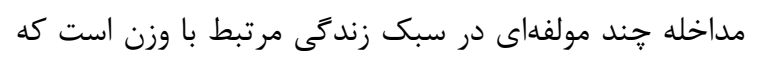

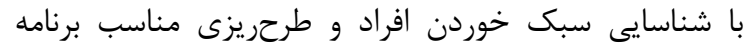

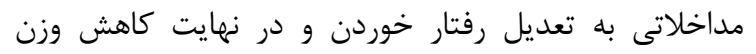

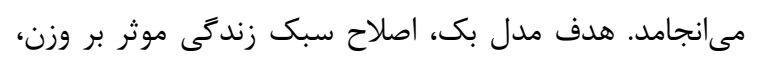

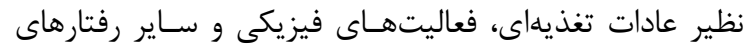

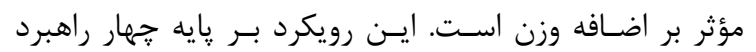

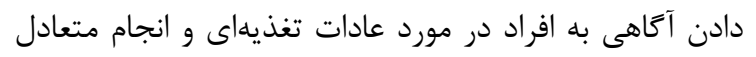

دارند و هردو بخشى از حوزه مشكلات وابسته به وزن هستند

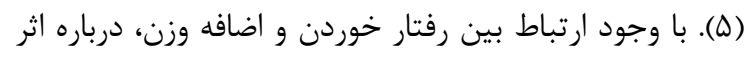

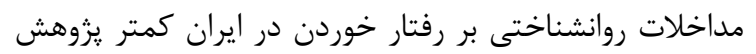

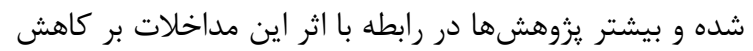

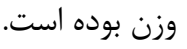
منظور از رفتار خوردن (Eating behavior)، سبك يا عاد است

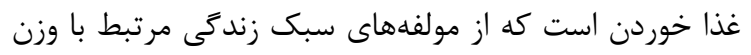

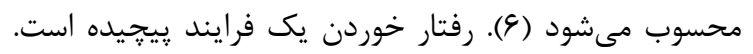

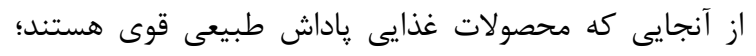

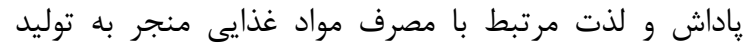

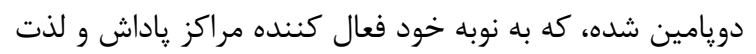

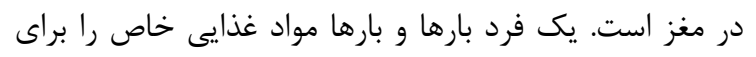

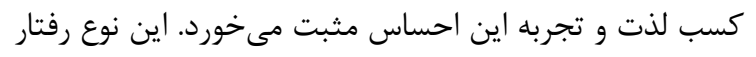

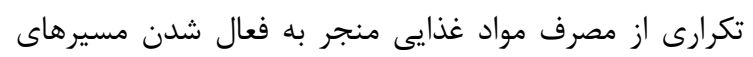

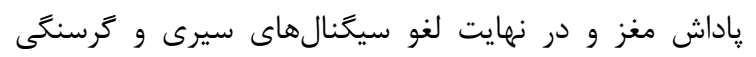

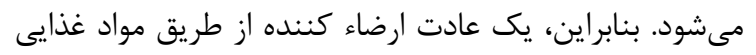

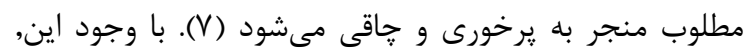

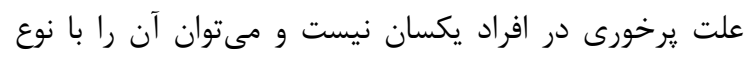

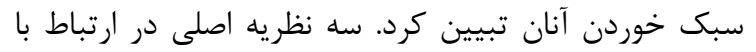

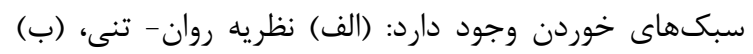

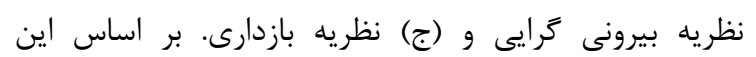

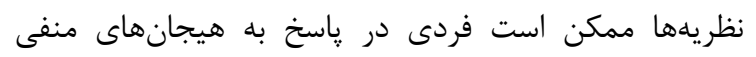

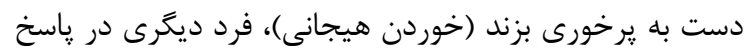

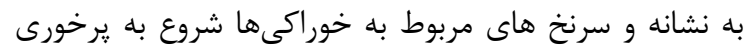

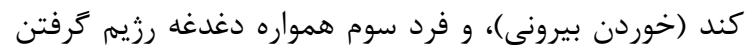

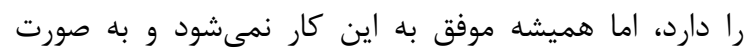

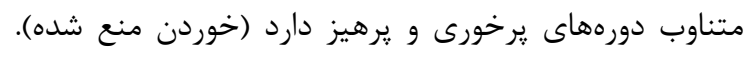

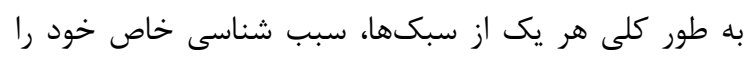

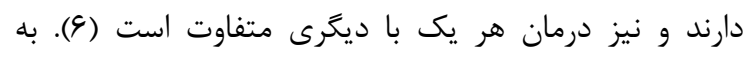

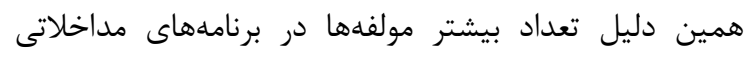

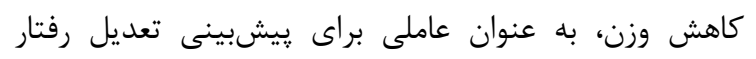

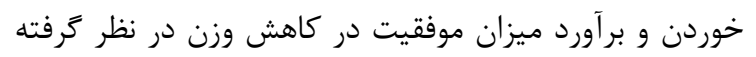

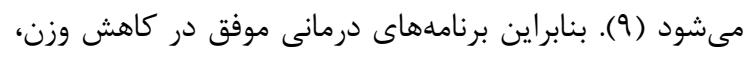

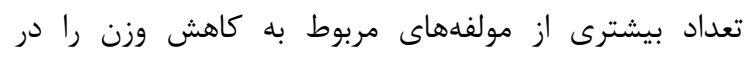

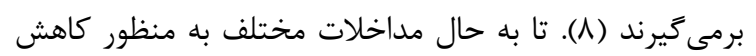

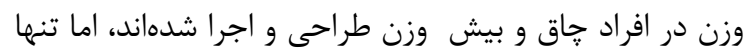

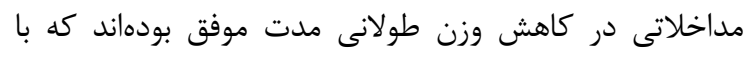

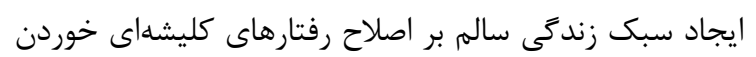

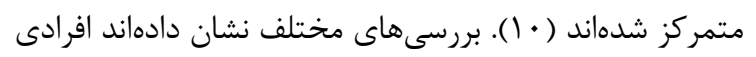

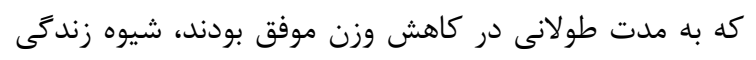


بين فا Tass Index [BMI]

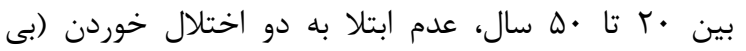

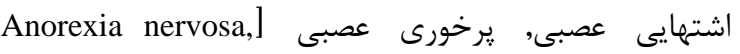
[Bulimia nervosa ذكر است كه به منظور ارزيابى و تشخيص اين دو اختلال بىاشتهايى عصبى و پرخورى عصبى از جـى ليست اختلالات

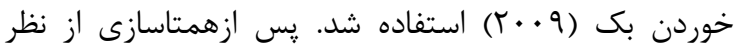
ويزگگ هاى جمعيت شناختى (سن، قد، وزن، نمايه توده بدنى)،

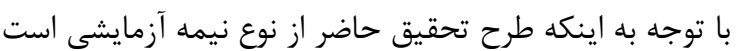
و براى تعيين حجم نمونه در تحقيقات آزمايشى و نيمه

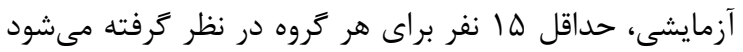
و با يك نمونه كمى بزرگتر محقق كمتر فرض صفر را در

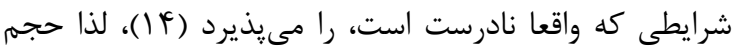
نمونه در يزوهش حاضر به صورت در دسترس و با در نظر

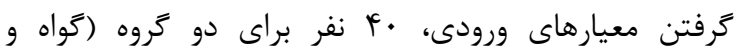

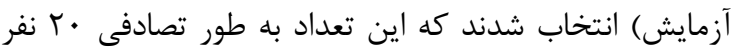

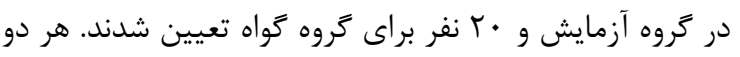

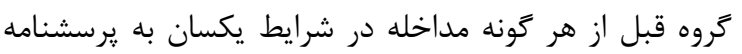

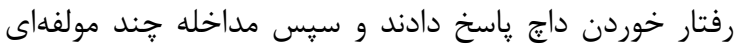

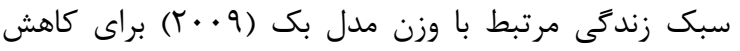
وزن انجام شد، به طورى كه برنامهاى هشت جلسهاى، هر مر بـ
فعاليت بدنى، اصلاح و كنترل محركهايى كه غذا خوردن را تحت تأثير قرار مىدهند، توسعه اصول و تكنيكهاى غذا غذا خوردن بـراى كنتـرل سرعت خوردن، و تشويق و ايجاد تقويـت مثبـت براى تثبـت و ايجاد انخيزه در كاهش وزئ وزئ

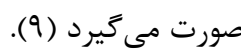
بنابراين، زيزوهش حاضر با هدف بررسى كارايى مدل جند مولفهاى سبك زندگى مرتبط با وزن بكى ( The Beck Diet

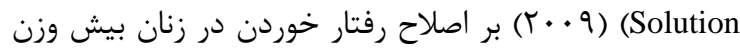

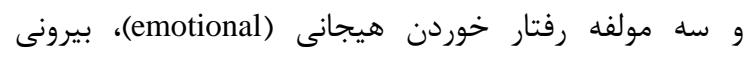
و منع شده (external)

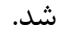

\section{مواد و روشها}

يزوهش حاضر به شيوه نيمه آزمايشى با طرح "ييش آزمون

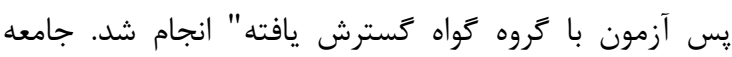
آمارى شامل كليه زنان دانشجوى بيش وزن دانشعاه آزاد اسلامى واحد كرج بود. نمونه آمارى مورد نظر از طريق نمونه گيرى در دسترس انتخاب شد.

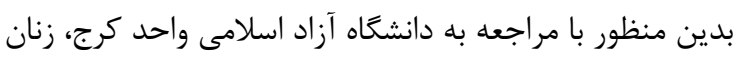
بيش وزن را شناسايى و يس از جلب رضايت آنان، افرادى از جامعه فوق با رعايت ملاكمايى نظير نمايه توده بدنى ( Body

\begin{tabular}{|c|c|}
\hline محتوا & جلسات \\
\hline 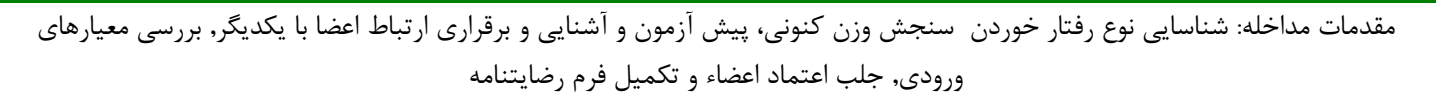 & اول \\
\hline 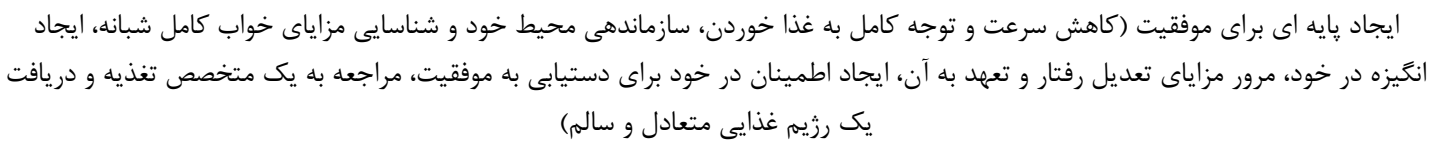 & دوم \\
\hline 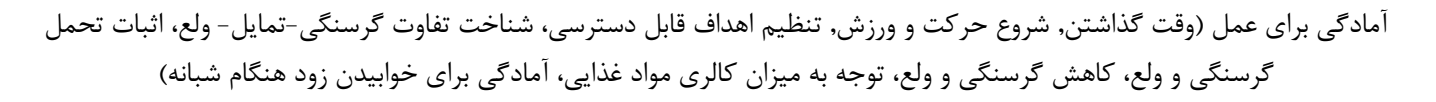 & سوم \\
\hline 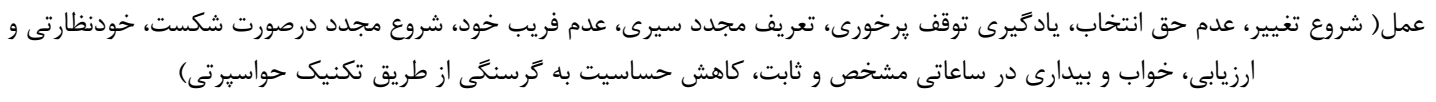 & קهارم \\
\hline 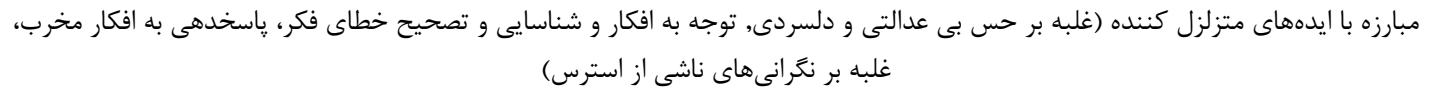 & ينجم \\
\hline 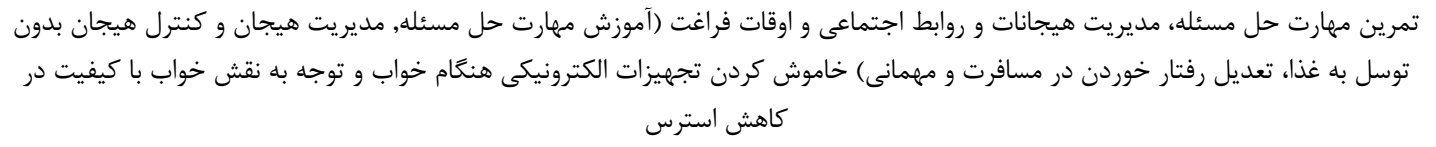 & ششم \\
\hline 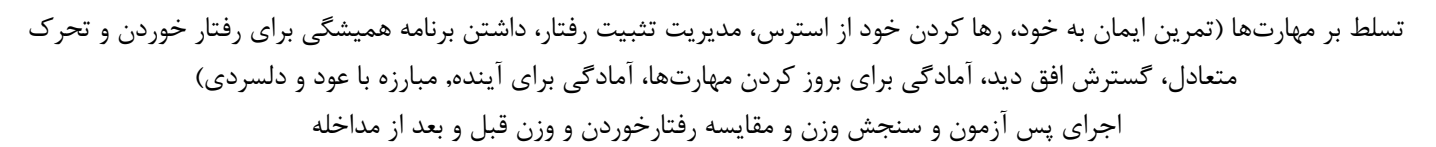 & هشتم \\
\hline
\end{tabular}


(Behaviour Questionnaire يرسشنامه يك مقياس خودسنجى است و به طور كلى شامل دو بخش است. بخش اول، مشخصات آزمودنى و و

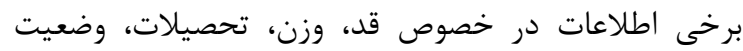
تاهل، نمايه توده بدنى، بيمارى، نوسانات وزن و وجود يا عدم وجود زيرخورىهاى دورهاى را در بر مى گيرد. بخش

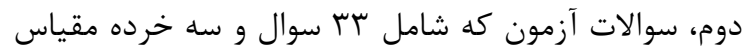
(مولفه) براى سنجش سبكهاى خوردن هيجانى (1T) يرسش)، خوردن بيرونى (· (1 يرسش)، و خوردن منع شده

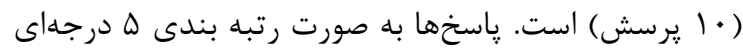

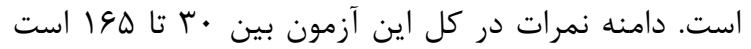
كه نمرات بالاتر بيانگر رفتار, خوردن نامتعادل است. يرسشنامه ياد شده توسط صالحى فدردى و همكارانش بـ بلات

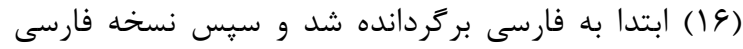

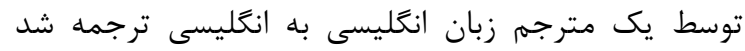

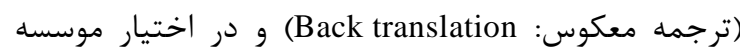

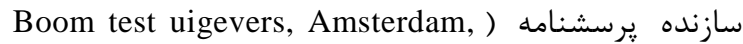
(The Netherlands كرونباخ بالا را براى كل مقياس و مولفههاى آن ززارش

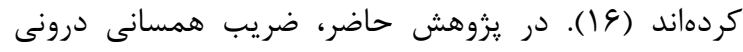

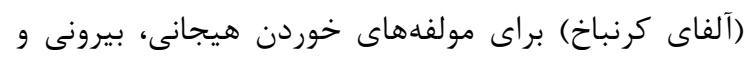

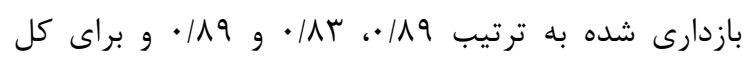

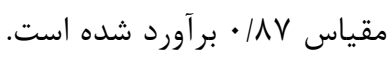

يروتكل مداخلهاى مورد استفاده در يزوهش حاضر مدل

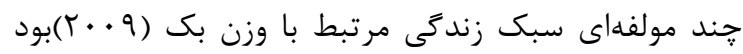
كه خلاصه جلسات مداخله در جدول ا آمده است.
جلسه · ج دقيقه، به صورت گروهى براى گروه آزمايش اجرا

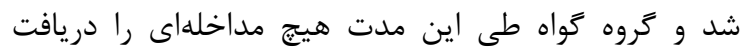

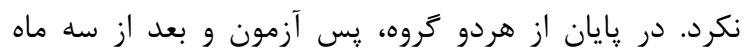
ييگيرى به عمل آمد. جهت رعايت اصول اخلاقى، گروه گوراه

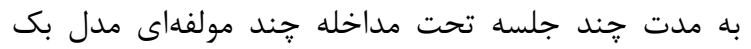

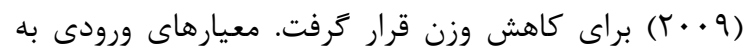

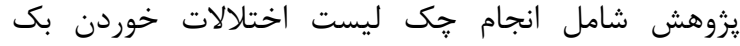

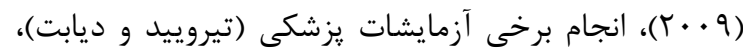

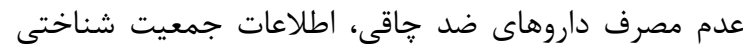
از قبيل زنان دانشجوى دانشخاه آزاد اسلامى واحد كرج با

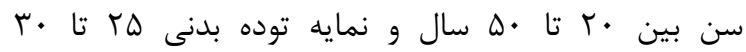

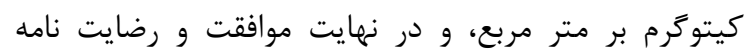
كتبى براى شركت در يروهش بود. ملاكهاى خروج شامل

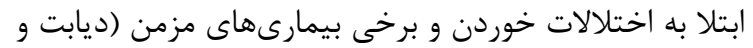

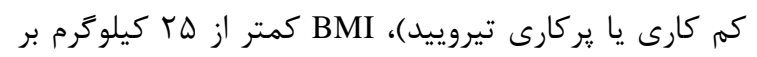

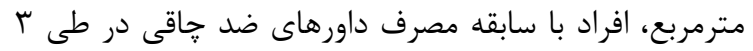

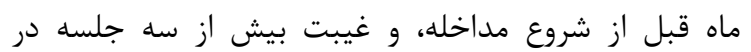

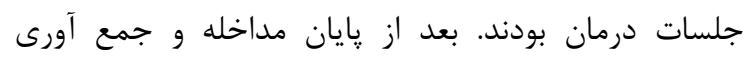
دادهها، يردازش آمارى لازم بر روى دادههاى خام با استفاده

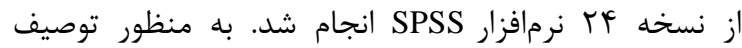

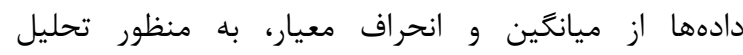

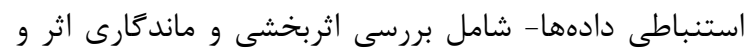

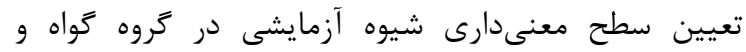

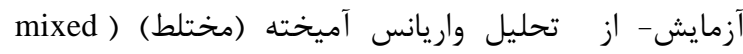
(ANOVA ) استفاده شد.

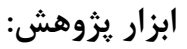
در يزوهش حاضر به منظور اندازه گيرى رفتار خوردن از

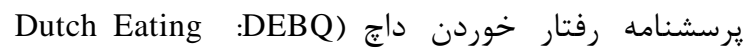

\begin{tabular}{|c|c|c|c|c|c|c|c|}
\hline \multicolumn{2}{|c|}{ ييخيرى } & \multicolumn{2}{|c|}{ يس ڤآزمون } & \multicolumn{2}{|c|}{ يِش آزمون } & \multirow[t]{2}{*}{ كروه } & \multirow[t]{2}{*}{ متغير / مولفه } \\
\hline SD & $\mathrm{M}$ & SD & $\mathrm{M}$ & SD & $\mathrm{M}$ & & \\
\hline $1 \pi / 9$. & $\Lambda F / r$. & $10 / 1 T$ & $V q / 9$. & $\mid \psi / \cdot \Lambda$ & $9 \Psi / 0$. & آزمايش & متغير كلى \\
\hline$\vee, \wedge \cdot$ & $৭ \Delta / \wedge$. & $9 / \cdot 1$ & Qr/vQ & $\Lambda / V \Delta$ & $9 q / \pi$. & كواه & رفتار خوردن \\
\hline$\Delta / 8 \Lambda$ & $r \& / 1$. & $F / V \Delta$ & $r F / V$. & $s / 4$. & $r \cdot 190$ & آزمايش & [مولفه] \\
\hline G/4G & TN/TH & $\mathrm{V} / \cdot \Lambda$ & $T V / F \Delta$ & $91 .$. & $r q / r$. & كواه & خوردن هيجانى \\
\hline ( ) & $r \wedge / 9 D$ & $9 / 09$ & $r \Delta / V \Delta$ & $\varepsilon / \pi V$ & $r r / F$. & آزمايش & [مولفه] \\
\hline $9 / \pi G$ & . & D/qF & rT/lQ & $\Delta / \Delta)$ & D & كواه & خوردن بيرونى \\
\hline V/re & $r q / \Delta \Delta$ & N/FT & $r \varepsilon / F \Delta$ & $\varepsilon / \Delta \Lambda$ & $r \cdot / F \Delta$ & آزمايش & [مولفه] \\
\hline$p / q$. & $r r / .$. & $\Delta / \uparrow \Delta$ & $r F / l Q$ & $f / \Delta q$ & rI/AD & كواه & خوردن منع شده \\
\hline
\end{tabular}


اسميرنوف در متغيرهاى مورد بررسى در هر سه نوبت اندازه

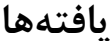

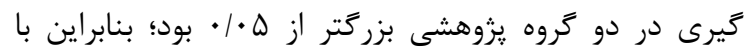

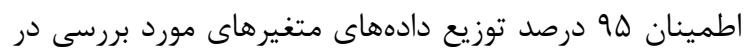

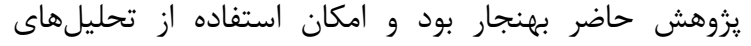
يارامتريكوجود داشت.

براى مشخص كردن معنى دارى تفاوت بين متغيرهاى يزوهش

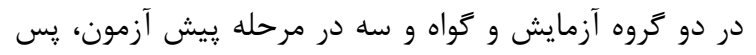

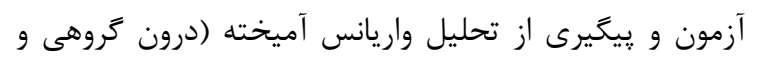

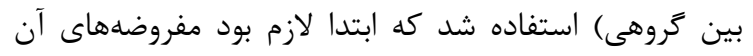

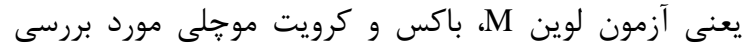

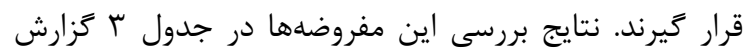

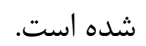
نتايج جدول r حاكى از عدم تخطى از مفروضههاى تحليل

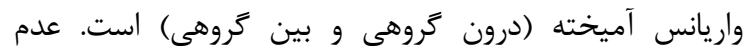

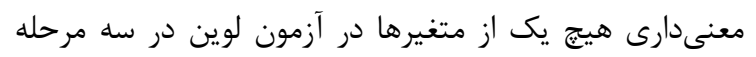

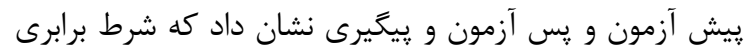

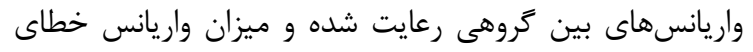

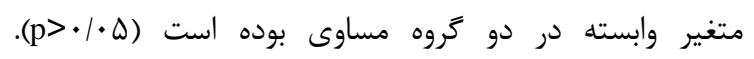

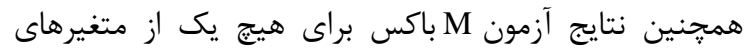

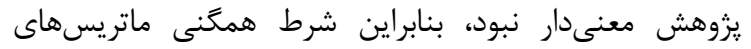

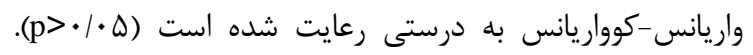

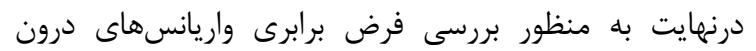

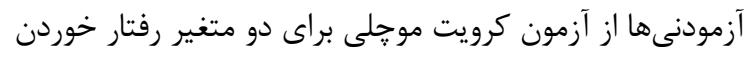

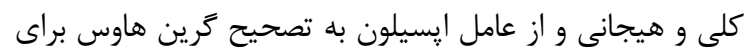

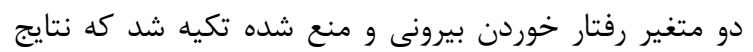

در رابطه با ويزگكىهاى جمعيت شناختى شركت كنندكان،

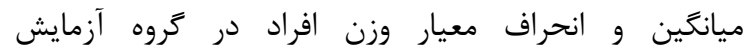
VN/G·(II/IT) ميانگين و انحراف معيار نمايه توده بدنى افراد

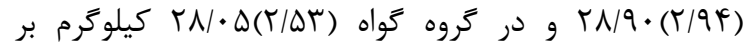

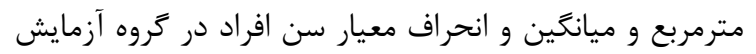

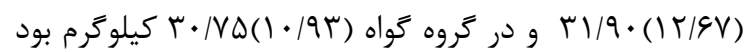

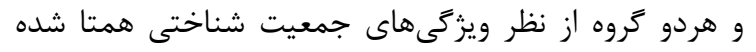

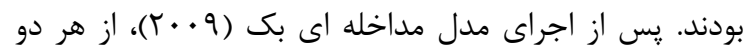

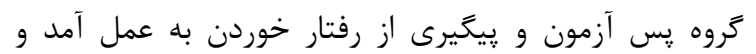

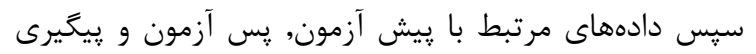

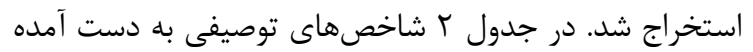

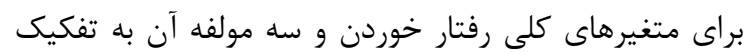

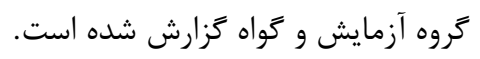

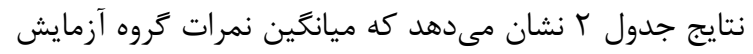

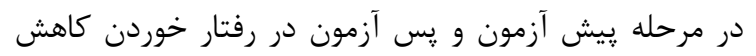

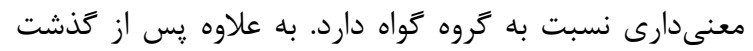

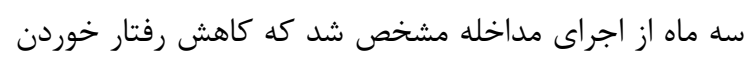

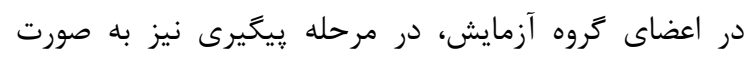

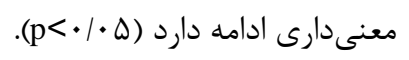

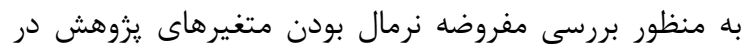

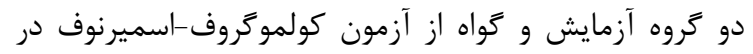

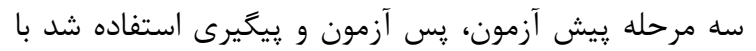

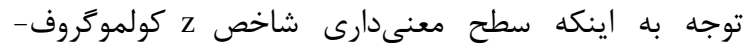

جدول س. نتايج بررسى مفروضه هاى تحليل واريانس آميخته(درون كروهى و بين كروهى)

\begin{tabular}{|c|c|c|c|c|c|}
\hline آزمون كرين هاوس & آزمون كرويت موجلى & آزمون M باكس & آزمون لوين & نوبت اجرا & متغير / مولفه \\
\hline & \multirow[t]{3}{*}{. TKK } & \multirow[t]{3}{*}{$\cdot / \pi r \Delta$} & . /Tr & يشي آزمون & ] \\
\hline & & & . & ي قِ آزمون & رفتار خوردن \\
\hline & & &.$/ N \mathrm{HV}$ & ييخيرى & كلى \\
\hline & \multirow[t]{3}{*}{$\cdot 1 \cdot V^{F}$} & \multirow[t]{3}{*}{$\cdot 11 \cdot 1$} &.$/ 4 I T$ & بيش آزمون & [ [مولفه] \\
\hline & & & .1 .95 & يِ آزمون & خوردن هيجانى \\
\hline & & & $\cdot / V r V$ & ي ييگيرى & \\
\hline \multirow[t]{3}{*}{ •/Vq4 } & & \multirow[t]{3}{*}{$\cdot / v \cdot 9$} & $\cdot / 9 \Delta \Delta$ & ي يِش آزمون & [مولفه] \\
\hline & & & $\cdot \mid A T \Lambda$ & يس آزمون & خوردن بيرونى \\
\hline & & & $\cdot 190$ & يِيَيرى & \\
\hline \multirow[t]{3}{*}{$\cdot / \Lambda \& V$} & & \multirow[t]{3}{*}{ 每 } & - MTY & ي بيش آزمون & [مولفه] \\
\hline & & & $\cdot / 1 \wedge \Delta$ & 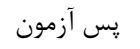 & خوردن منع شده \\
\hline & & & $\cdot 1 \cdot 19$ & ييخيرى & \\
\hline
\end{tabular}


جدول F. نتايج تحليل واريانس آميخته براى اثر اصلى زمان و تعامل بين زمان و كروه متغيير كلى رفتار خوردن و مولفه هاى آن

\begin{tabular}{|c|c|c|c|c|}
\hline $\mathrm{P}$ & مقدار F & ارزش & اثر & متغير / مولفه \\
\hline$\cdot / \ldots$ & TE/TT & & زمان اندازه كيرى & متغيير كلى \\
\hline$\cdot / \ldots$ & $19 / 91$ & $\cdot \mid F \wedge \Delta$ & تعامل زمان و كروه & رفتار خوردن \\
\hline$\cdot / \ldots$ & $1 T / 9$. & $\cdot 1019$ & زمان اندازه كيرى & [مولفه] \\
\hline . $/ F T$ &.$/ T H a$ & . /NFr & تعامل زمان و كروه لامبدا) & خوردن هيجانى \\
\hline$\cdot / \cdots$ & $1 \cdot|r|$ &. $\mid g 44$ & زمقان اندازه كيرى لامبدا) & [مولفه] \\
\hline .1 .19 & $F / F 1$ & $\cdot \mid \lambda \cdot V$ & تعامل زمان و كروه & خوردن بيرونى \\
\hline$\cdot / \pi \cdot 4$ & $1 / T T$ & . /9४ & زمان اندازه كيرى & [مولفه] \\
\hline$\cdot / \cdots$ & $1 . / \Delta F$ & . 1949 & تعامل زمان و كروه لامبدا) & خوردن منع شده \\
\hline
\end{tabular}

كروه به لحاظ آمارى معنىدار است. يعنى بين نمرات رفتار

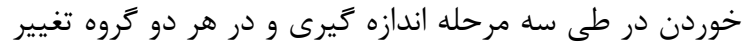

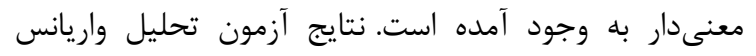

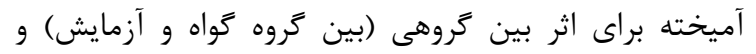

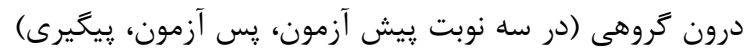

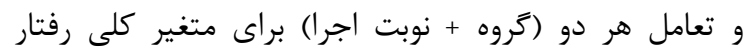

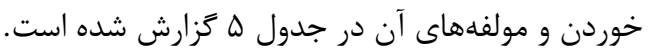
نتايج جدول ه نشان مىدهد، معنى دارى اثر عامل بين كروهي

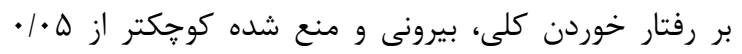

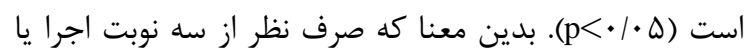
اندازه گيرى متغير وابسته, تفاوت معنى دار بين دو كروه كواه

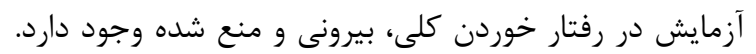

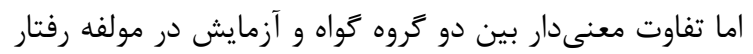

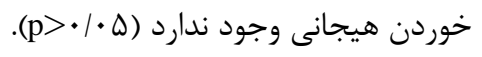
در بررسى تفاوت درون كروهى مى توان مشاهده كرد كه اثر

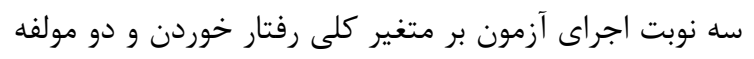

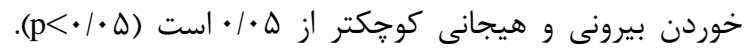

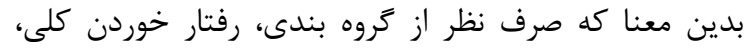

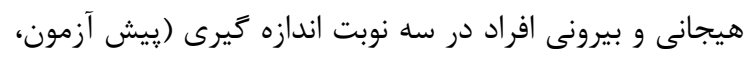

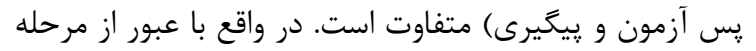
اول به سوم، تغييرات محسوسى در اين متغيرها ايجاد شده
اين بررسى نيز نشان دهنده عدم تخطى از اين مفروضه است

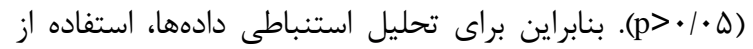

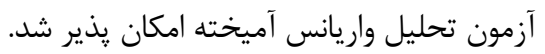

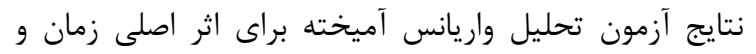

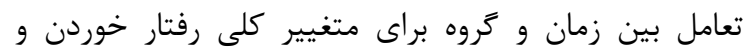

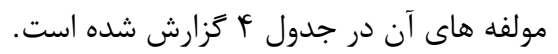

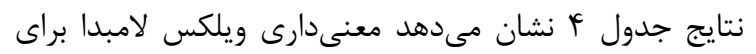
اثر اصلى زمان اندازه كيرى براى متغير كلى رفتار خوردن

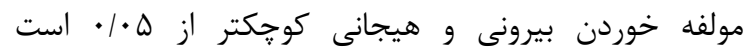

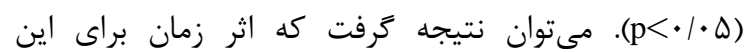

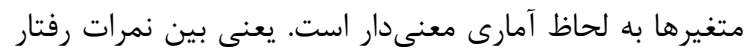

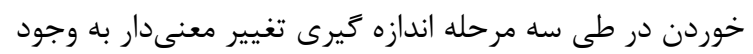

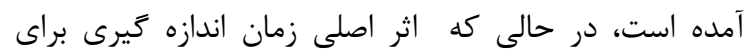

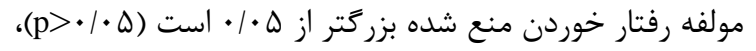

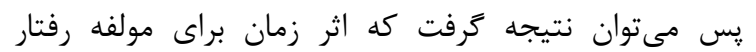

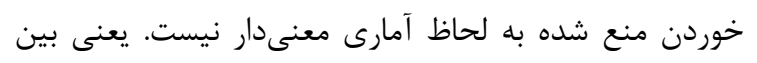

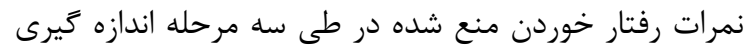
تغيير معنى دار به وجود نيامده است.

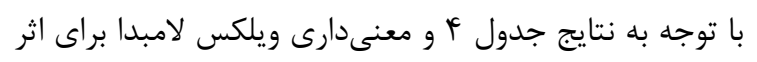

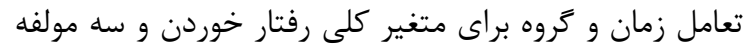

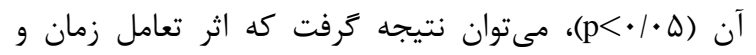


دلايل دامنه تغيير قابل توجه نمرات رفتار خوردن از بيش

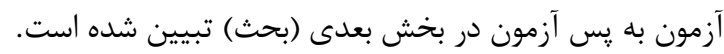

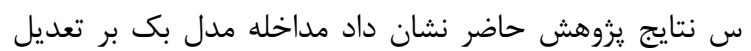
متغير كلى رفتارخوردن و مولفههاى آن (رفتار خوردن هيجانى،

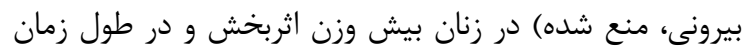

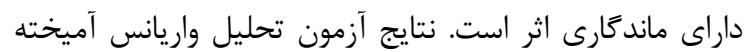

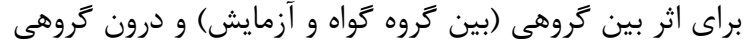

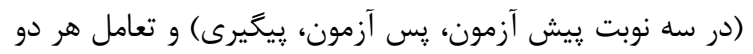
(كروه + نوبت اجرا) براى متغير كلى رفتار خوردن و ودون مولفههاى

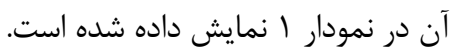

\section{بحث}

هدف يزوهش حاضر، بررسى كارايى مدل جند مولفهاى سبك

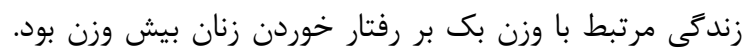

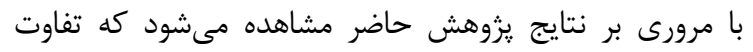

است. اما تفاوت معنىدار بين سه نوبت اندازه گيرى در مولفه رفتار خوردن منع شده وجود ندارد (ه •/ (p). از يافتههاى جدول ه متوجه مىشويم كه اثر تعاملى عوامل بين گروهى و درون گروهى بر رفتار خوردن و كليه مولفههاى

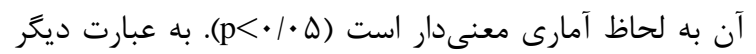

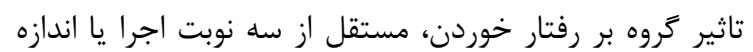

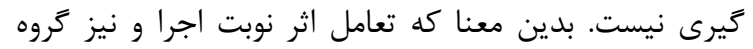

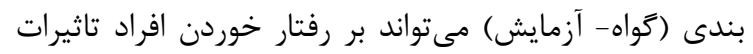

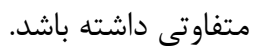
نتايج آزمون تعقيبى نيز نشان داد كه در مرحله يِيش آزماتهون

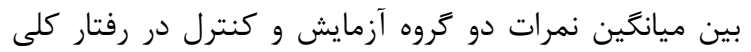

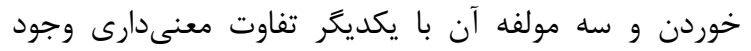

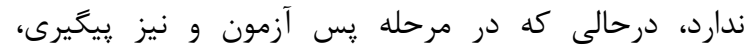

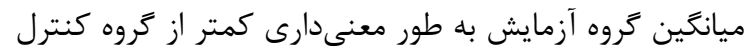

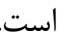

جدول ه. نتايج تحليل واريانس آميخته اثربين گروهى و درون كروهى و تعامل هر دو در متغير كلى رفتار خوردن و مولفه هاى آن مجان

\begin{tabular}{|c|c|c|c|c|c|c|}
\hline $\mathrm{P}$ & $\mathrm{F}$ & ميانكَين مجذورات & Df & مجموع مجذورات & منبع واريانس & متغير / مولفه \\
\hline \multirow[t]{2}{*}{$.1 . .4$} & $\Lambda / \Delta \cdot \Lambda$ & $r \wedge r T / F \cdot \Lambda$ & 1 & $r \Lambda T r / F \cdot \Lambda$ & اثر بين گَروهى & \\
\hline & & rrr/q.l & rs & $\mid r \varepsilon \Delta \cdot / r \Delta$. & (كروه كواه و آزمايش) & متغيير كلى \\
\hline \multirow[t]{2}{*}{$\cdot 1 \cdots$} & $r \cdot / l$. & $V T V / \Delta \Delta \Lambda$ & r & IFVD/VIV & اثر درون كروهى & رفتار خوردن \\
\hline & & $r G / v \cdot q$ & ve & rマ^q/q.. & (سه نوبت اجرا) & \\
\hline \multirow[t]{2}{*}{$\cdot \cdots$} & $1 N / 19 F$ & $99 \mathrm{~V} / \Lambda \Delta \Lambda$ & r & Irra/VIV & خطاى درون كروهى اثر & \\
\hline & & & & & تعاملى(كروه+نوبت اجرا) & \\
\hline \multirow[t]{2}{*}{$\cdot / 4 \vee \wedge$} & . & EF/AVD & 1 & FF/AVD & اثر بين كَروهى & \\
\hline & & ११/rॅם & rı & TFV.NIV & (كروه كواه و آزمايش) & خوردن هيجانى \\
\hline \multirow[t]{2}{*}{$\cdot \%$} & $19 / 0 \cdot V$ & $\mid \varepsilon \Delta / 1 \ldots$ & r & $r r \cdot / r \cdot$. & اثر درون كروهى & \\
\hline & & $1 \cdot / \cdot r$ & Ve & VG./Irr & (سه نوبت اجرا) & \\
\hline .1 .11 & $F / N<q$ & $\varepsilon V / \Delta$. & r & $q \Delta / \cdots$ & 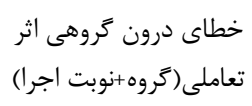 & \\
\hline \multirow[t]{2}{*}{. } & D/GYA & FGF/IRT & 1 & FAF/ITr & اثر بين كروهى & \\
\hline & & $\Lambda T / F V F$ & ru & MITF/... & (كروه كواه و آزمايش) & [مولفه] \\
\hline \multirow[t]{2}{*}{$\cdot 1 \cdots$} & N/^৭4 & IFT/QVD & r & $r \wedge \Delta / 9 \Delta$. & اثر درون كروهى & خوردن بيرونى \\
\hline & & $|9| \cdot V \mid$ & ve & $|r T| / F \cdot$. & (سه نوبت اجرا) & \\
\hline \multirow[t]{2}{*}{$\cdot 1 . .9$} & $\Delta / \uparrow \Delta$ & $\Lambda V / 9 \Delta \Lambda$ & r & $|V \Delta / r| V$ & خطاى درون كروهى اثر & \\
\hline & & & & & تعاملى(كروه+نوبت اجرا) & \\
\hline \multirow[t]{2}{*}{.1 .19} & $8 / r \cdot V$ & $9 \mid r / \cdot \cdots 1$ & 1 & $9 \mid r / \cdot \cdots 1$ & اثر بين كروهى & \\
\hline & & $q \mathrm{Q} / \cdot \mathrm{qr}$ & ru & rGAVIGD. & (كروه كَواه و آزمايش) & . \\
\hline \multirow[t]{2}{*}{ •/ VVD } & I/VAr & rI/9TA & r & $r r / \wedge \Delta$. & اثر درون كروهى & خوردن منع شده \\
\hline & & $1 \pi / r q 4$ & ve & $q K F / T .$. & (سه نوبت اجرا) & \\
\hline.$/ . .1$ & $N / \cdot V^{4}$ & $99 / \Gamma \Delta \wedge$ & $r$ & $19 \mathrm{~N} / 01 \mathrm{~V}$ & خطاملى درون كَروهى اثراثر & \\
\hline
\end{tabular}




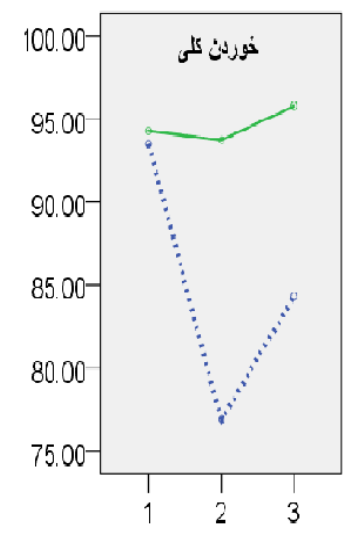

time

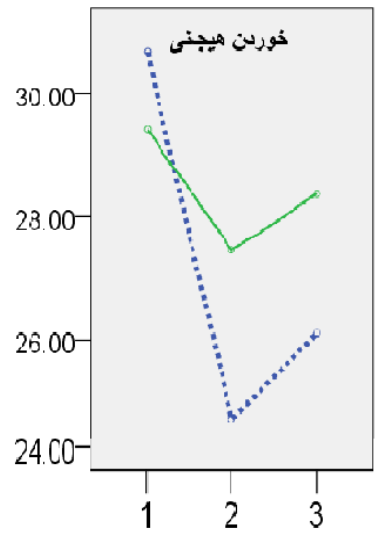

time

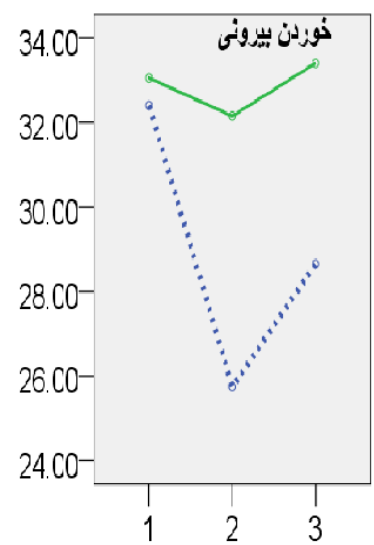

time

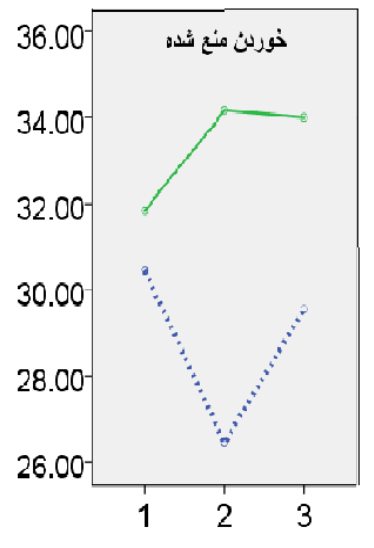

time

$$
\text { نمودار ا. نمودارهاى بين گروهى, درون گروهى و تعاملى رفتار خوردن كلى و سه مولفه آن }
$$

از آنجايى كه يكى از دلايل موثر بر ميزان موفقيت يا عدم

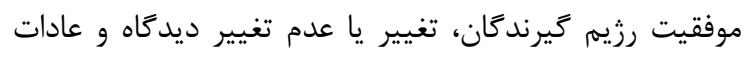

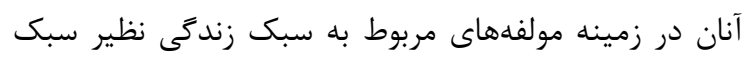

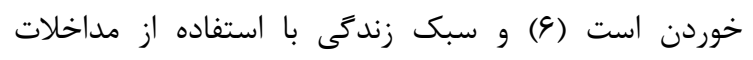

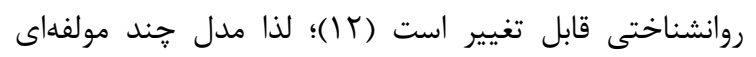

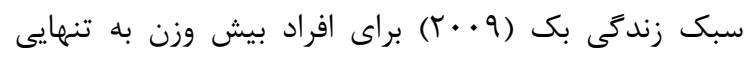

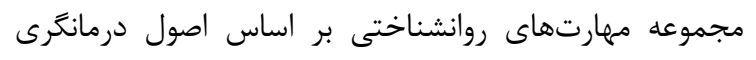

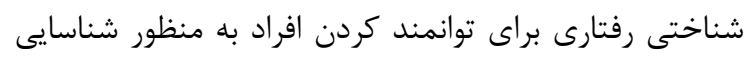

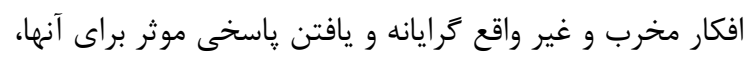

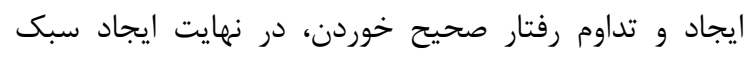

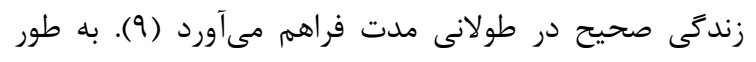

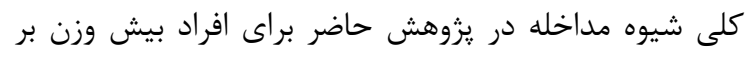

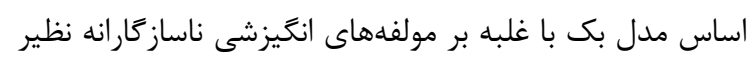
ناميدى و عدم آكاهى در موفقيت، تعهد ناكافى براى دستيه بر مدليابى ناسيى به هدف، احساس كنترل קايين و كمبود مشوقها و و اهداف

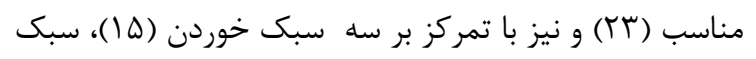

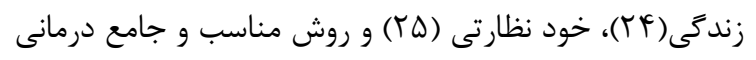

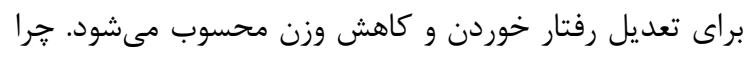

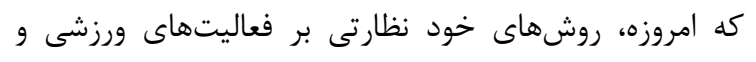

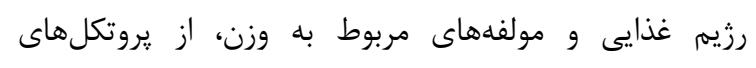

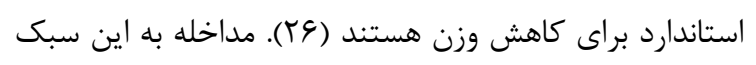

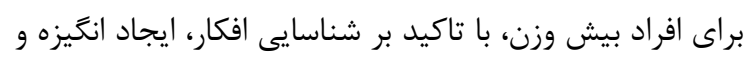

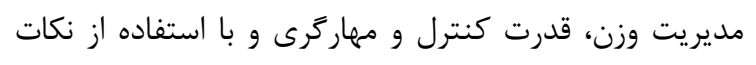

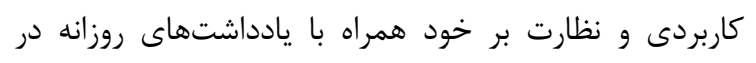

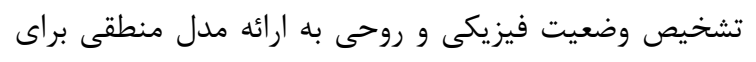

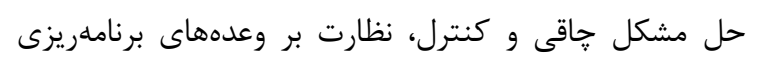

معنى دار بين دو گروه گ گواه و آزمايش (اثر عامل بين گروهى) در

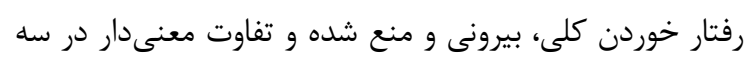

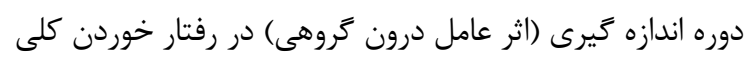

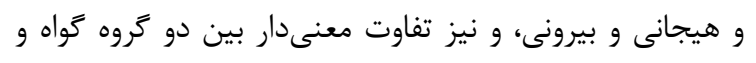

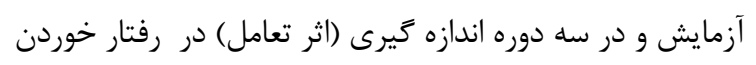

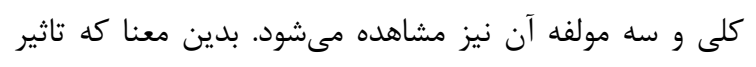

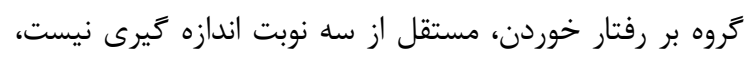

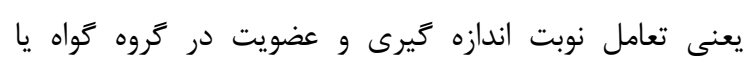

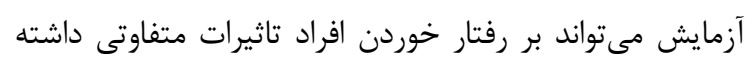

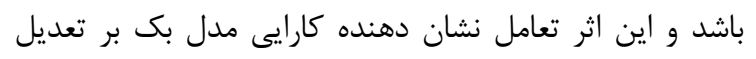
رفتار خوردن و سه مولفه آن است.

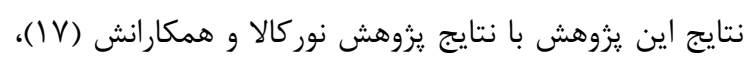

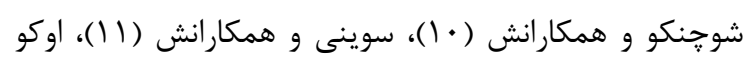

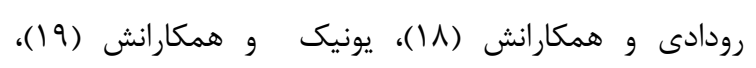

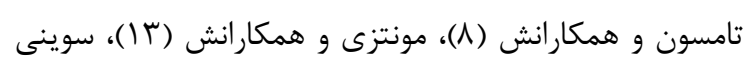

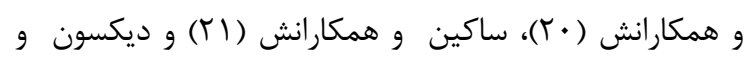

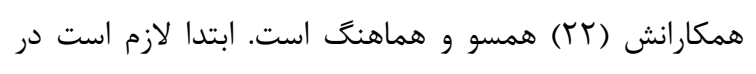

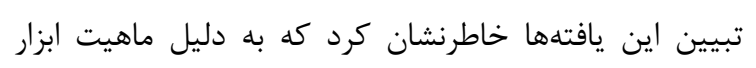

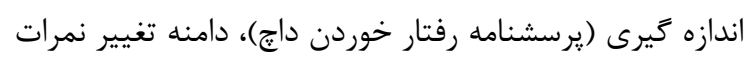

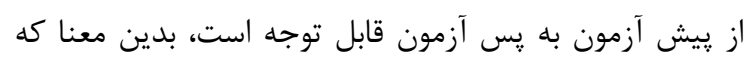

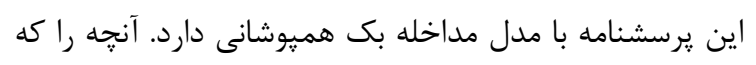

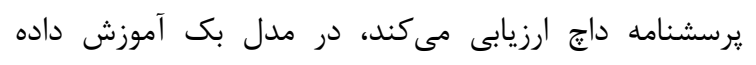

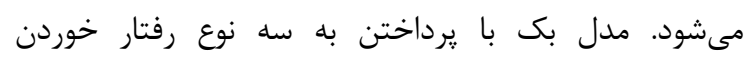

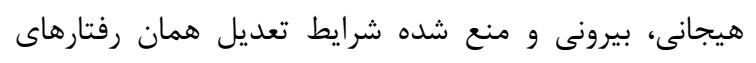

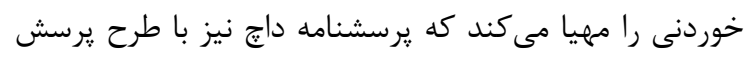
هايى اين سه رفتار را به طور مستقيم اندازه كيرى مئ كند. 
هرا كه استرس منجر به مشكلات عاطفى و افزايش كورتيزول

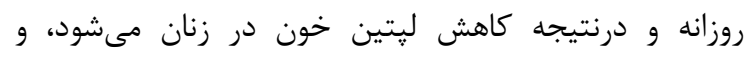

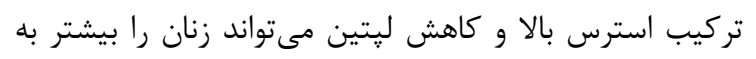

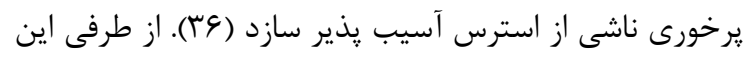

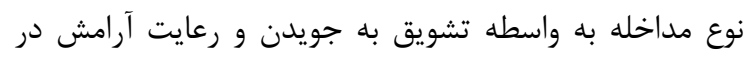

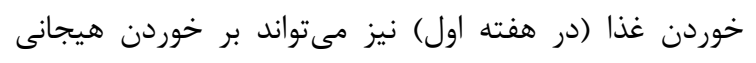

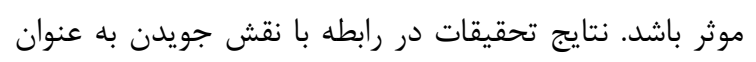

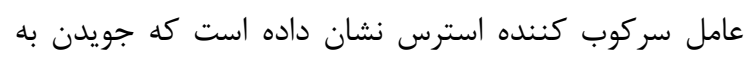

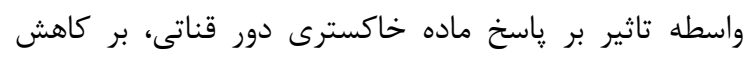

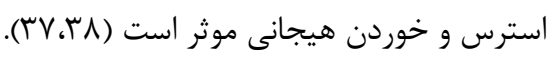

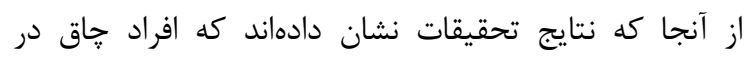

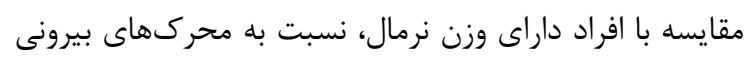

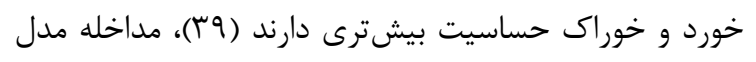

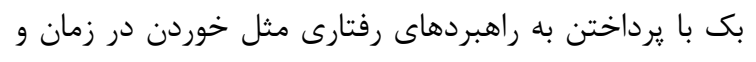

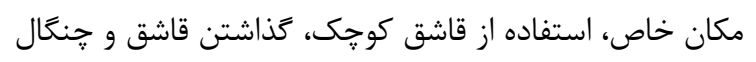

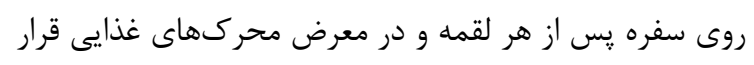

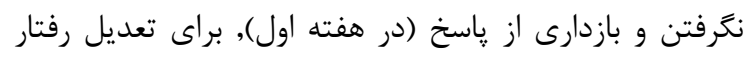
خوردن بيرونى نيز موثر شناخته شده است. بهعلاوه با تمركز

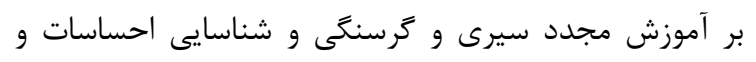

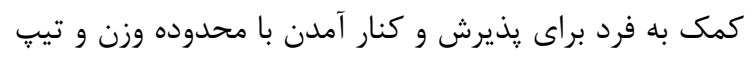

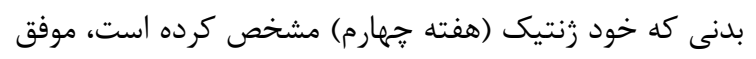

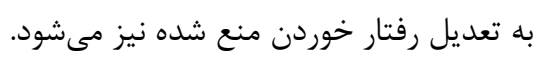
به طور كلى نتايج تحقيقات مختلف نشان دادهاند كه تغييرات

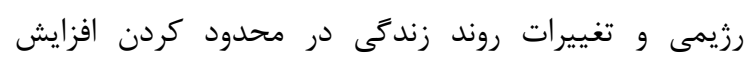

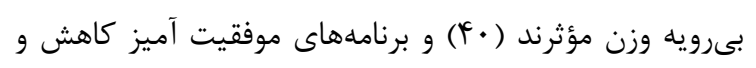

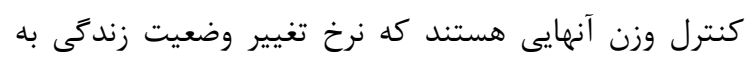

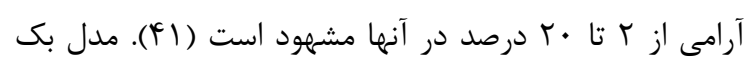

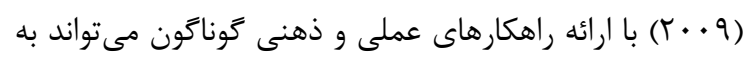

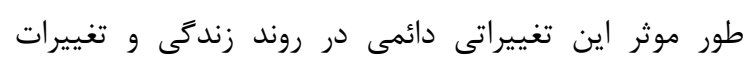

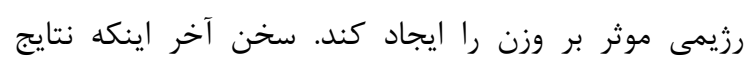

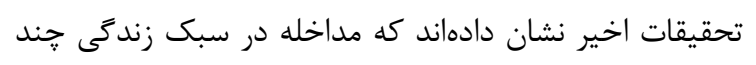

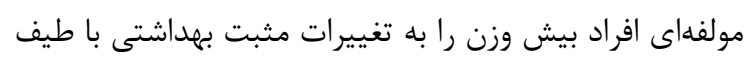

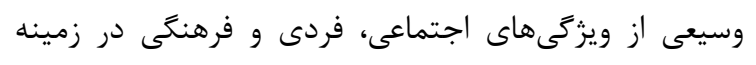

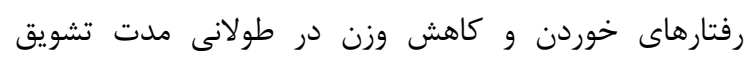

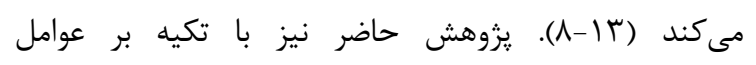

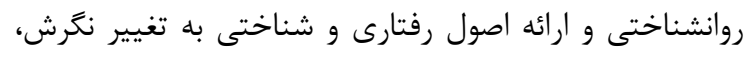

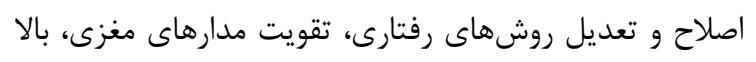

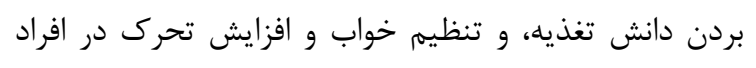

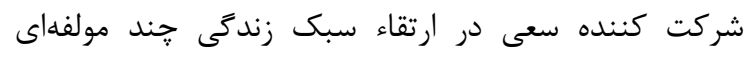

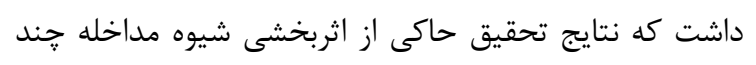

نشده و دسترسى به غذا و هيجانهاى منفى و..... با ارائه

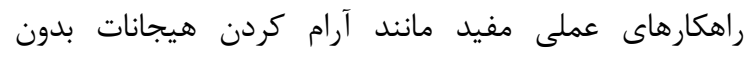

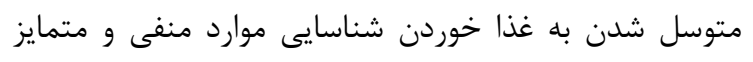

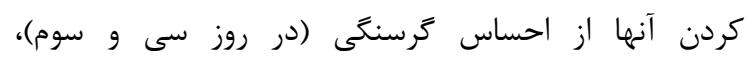

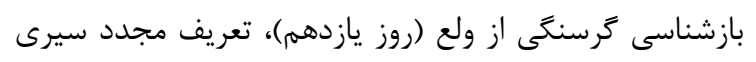

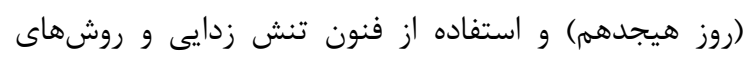

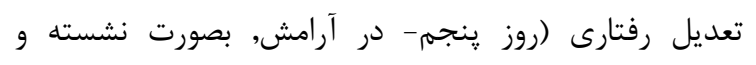

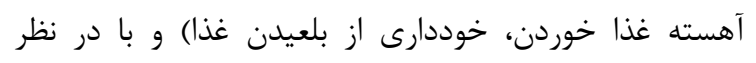

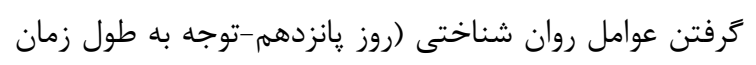

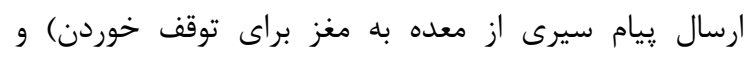

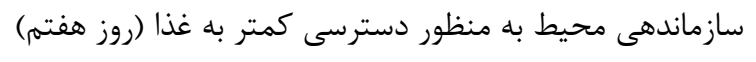

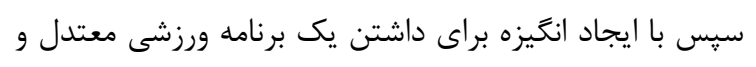

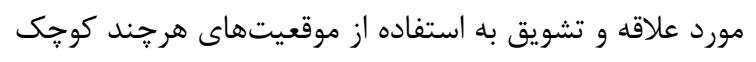
براى ايجاد تحرك و فعاليت بدنى طورى كه بتوان آنها را براى تونى

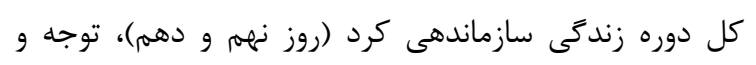
مديريت اوقات فراغت مثل مهمانى و مسافرت، اصلاح روابط دماند

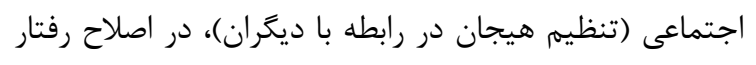

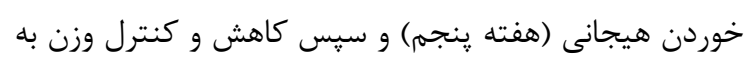

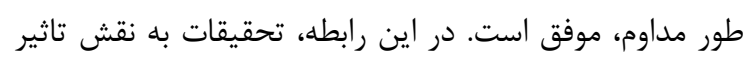

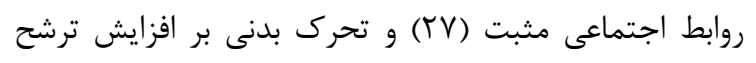

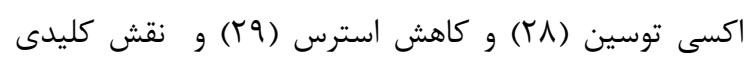

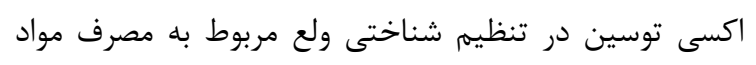

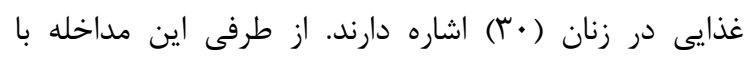

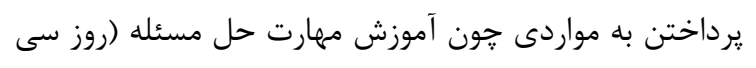

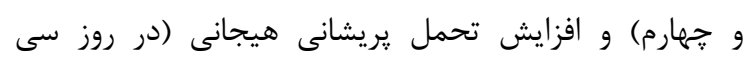

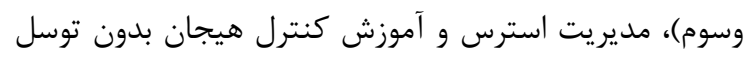

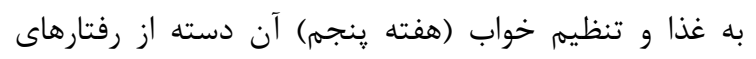

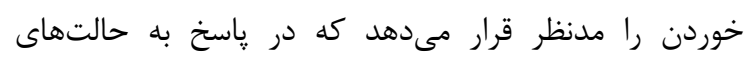

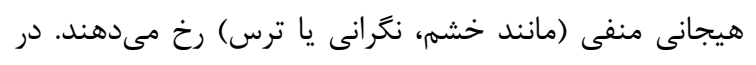

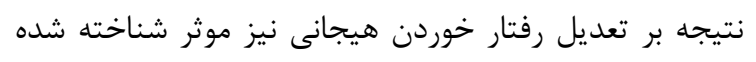

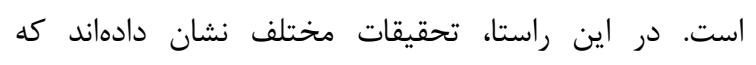

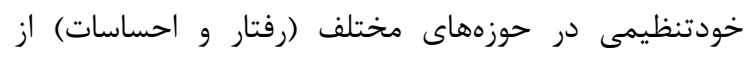

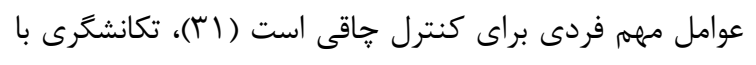

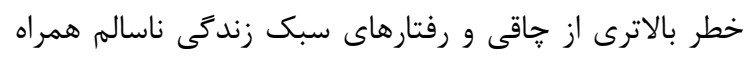

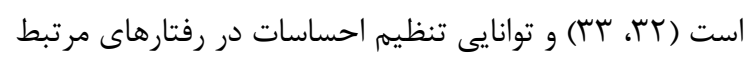
با كاهش وزن موثر است (YY)

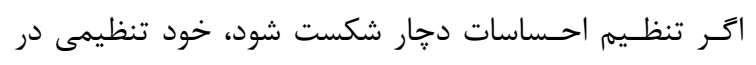

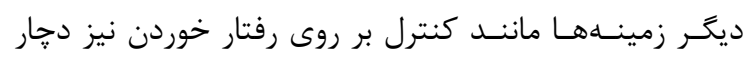

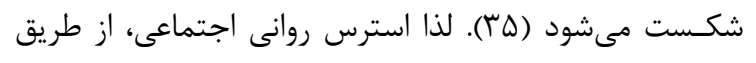

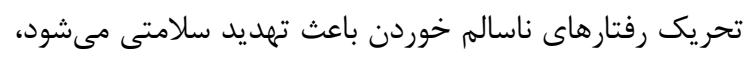




\section{تشكر و قدردانى}

مولفهاى متمركز بر سبك زندگى مرتبط با وزن در تعديل

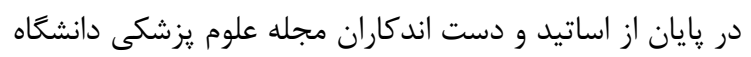

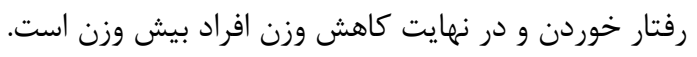

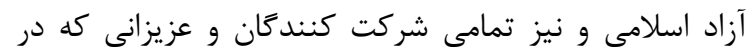
اين يزوهش ما را يارى نمودند، سياسخزارى مىنماييم.

\section{REFERENCES}

1. Azizi F, Azad bakht L, Mirmiran P. Prevalence of Overweight, Obesity and Abdominal Obesity in Adults 13 Years Tehran 1998-2001. J Med Shahid Beheshti Univ Med Sci 2005;29:123-9. ]in Persian[

2. Monfared AB, Hatami H, Isabeiglou H. Prevalence and associated factors of overweight and obesity in reproductiveaged women in Rasht. Journal of Health in the Field 2016;4.]in Persian[

3. Zar A, Karan Khosravi P, Ahmadi Mohammad M. The prevalence of obesity and overweight in female students of Shiraz University of Medical Sciences and their relationship with physical fitness factors. J Community Health 2017;4:79-89. ]in Persian[

4. Hill AJ. Motivation for eating behaviour in adolescent girls: the body beautiful. Proc Nutr Soc 2006;65:376-84.

5. Neumark-Sztainer D. Obesity and eating disorder prevention: an integrated approach? Adolesc Med 2003;14:159-73.

6. Van Strien T, Herman CP, Verheijden MW. Eating style, overeating and weight gain. A prospective 2-year follow-up study in a representative Dutch sample. Appetite 2012;59:782-9.

7. Singh M. Mood, food, and obesity. Front Psychol 2014;5:925.

8. Thomson JL, Zoellner JM, Tussing-Humphreys LM, Goodman MH. Moderators of intervention dose effects on diet quality and physical activity changes in a church-based, multicomponent, lifestyle study: Delta Body and Soul III. Health Educ Res 2016;31:339-49.

9. Beck JS. The Beck Diet Solution: Train Your Brain to Think Like a Thin Person. United States of America: Oxmoor House, 2009.

10. Shevchenko Y, Vesnina L, Kaydashev I. Features Of Eating Behavior In Persons With Normal And Increased Body Weight. Fiziol Zh 2015;61:51-8.

11. Soini S, Mustajoki P, Eriksson JG. Lifestyle-related factors associated with successful weight loss. Ann Med 2015;47:88-93.

12. Shaw JW, Johnson JA, Coons SJ. US valuation of the EQ-5D health states. Med Care 2005;43:203-20.

13. Montesi L, Ghoch ME, Brodosi L, Calugi S, Marchesini G Grave, R Dalle. Long-term weight loss maintenance for obesity: a multidisciplinary approach. Diabetes Metab Syndr Obes 2016;9:37-46.

14. Delaware Ali. Theoretical and practical basis of research in humanities and social sciences. Tehran: Roshd publication, 2008. ]in Persian[

15. Van Strien T. Dutch eating behavior questionnaire: Manual. Edmunds : Thames Valley Test Company, 2002.

16. Salhei-Fadardi J, Moghaddaszadeh-Bazzaz M, AminYazdi A, Nemati M. The role of attentional bias and eating styles in dieters. J Clin Psychol 2013;5:57-67.]in Persian[

17. Nurkkala M, Kaikkonen K, Vanhala ML, Karhunen L, Keränen AM, Korpelainen R. Lifestyle intervention has a beneficial effect on eating behavior and long-term weight loss in obese adults. Eat Behav 2015;18:179-85.

18. Okorodudu DE, Bosworth HB, Corsino L. Innovative interventions to promote behavioral change in overweight or obese individuals: A review of the literature. Ann Med 2015;47:179-85.

19. Unick JL, Neiberg RH, Hogan PE, Cheskin LJ, Dutton GR, Jeffery R, et al . Weight change in the first 2 months of a lifestyle intervention predicts weight changes 8 years later. Obesity (Silver Spring) 2015;23:1353-6.

20. Soini S, Mustajoki P, Eriksson JG. Weight loss methods and changes in eating habits among successful weight losers. Ann Med 2016;48:76-82.

21. Sakane N, Sato J, Tsushita K, Tsujii S, Kotani K, Tominaga M, et al. Effects of lifestyle intervention on weight and metabolic parameters in patients with impaired glucose tolerance related to beta-3 adrenergic receptor gene polymorphism Trp64Arg(C/T): results from the Japan Diabetes Prevention Program. J Diabetes Investig 2016;7:338-42.

22. Dixon H, Murphy M, Scully M, Rose M, Cotter T. Identifying effective healthy weight and lifestyle advertisements: Focus groups with Australian adults. Appetite 2016;103:184-91. 
23. Cox WM, Klinger E. Systematic motivational counseling: from motivational assessment to motivational change. In: Cox WM, Klinger E, Eds. Handbook of motivational counseling: goal-based approaches to assessment and intervention with addiction and other problems. Chichester, UK: Wiley-Blackwell; 2011. pp. 275-302.

24. Brownell KD. The LEARN program for weight management 10th Ed. Dallas: American Health Publishing, 2004.

25. Wadden TA, Butryn ML, Wilson C. Lifestyle modification for the management of obesity. Gastroenterology 2007;132:226-28.

26. Jacob JJ, Isaac R. Behavioral therapy for management of obesity. Indian J Endocrinol Metab 2012;16:28-32.

27. Rault JL. Effects of positive and negative human contacts and intranasal oxytocin on cerebrospinal fluid oxytocin. Psychoneuroendocrinology 2016;69:60-6.

28. Frisén LW. Training and hormones in physically active women: with and without oral contraceptive use [PhD Thesis]. Umeå University, Faculty of Medicine, Department of Community Medicine and Rehabilitation, Sports medicine; Sweden; 2016.

29. Jackson EM. Stress relief: The role of exercise in stress management. ACSM s Health Fit J 2013;17:14-19.

30. Striepens N, Schröter F, Stoffel-Wagner B, Maier W, Hurlemann R, Scheele D. Oxytocin enhances cognitive control of food craving in women. Hum Brain Mapp 2016;37:4276-85.

31. Graziano PA, Calkins SD, Keane SP. Toddler self-regulation skills predict risk for pediatric obesity. Int J Obes (Lond) 2010;34:633-41.

32. Evans GW, Fuller-Rowell TE, Doan SN. Childhood cumulative risk and obesity: the mediating role of selfregulatory ability. Pediatrics 2012;129:68-73.

33. Francis LA, Susman EJ. Self-regulation and rapid weight gain in children from age 3 to 12 years. Arch Pediatr Adolesc Med 2009;163:297-302.

34. Isasi CR, Ostrovsky NW, Wills TA. The association of emotion regulation with lifestyle behaviors in inner-city adolescents. Eat Behav 2013;14:518-21.

35. Leehr EH, Krohmer K, Schag K, Dresler T, Zipfel S, Giel KE. Emotion regulation model in binge eating disorder and obesitya systematic review. Neurosci Biobehav Rev 2015;49:125-34.

36. Michels N, Sioen I, Ruige J, De Henauw S. Children's psychosocial stress and emotional eating: A role for leptin? Int J Eat Disord 2017;50:471-80.

37. Hirano Y, Onozuka M. Chewing and attention: a positive effect on sustained attention. BioMed Res Int 2014;2015:6.

38. Yamada K, Narimatsu Y, Ono Y, Sasaguri K, Onozuka M, Kawata T, et al. Chewing suppresses the stressinduced increase in the number of pERK-immunoreactive cells in the periaqueductal grey. Neurosci Lett 2015;599:438.

39. Taghavi MR, Tavoosi AR, Godarzi MA. The correction program focuses on Changing the Attention of Obese Women to Food Signs. Journal of Psychological Methods and Models 2016;7:1-10. ]in Persian[

40. Thangaratinam S, Rogozinska E, Jolly K, Glinkowski S, Roseboom T, Tomlinson, et al. Effects of interventions in pregnancy on maternal weight and obstetric outcomes: meta-analysis of randomised evidence. BMJ 2012;344:2088.

41. Wing RR, Phelan S. Long-term weight loss maintenance. Am J Clin Nutr 2005;82:222S-5. 